\title{
Review
}

Journal of Innate

Immunity
J Innate Immun 2012;4:437-445

DOI: $\underline{10.1159 / 000335216}$
Received: October 4, 2011

Accepted after revision: November 18, 2011

Published online: February 7, 2012

\section{Innate Immune Functions of Macrophage Subpopulations in the Spleen}

\author{
Joke M.M. den Haan Georg Kraal \\ Department of Molecular Cell Biology and Immunology, Vrije University Medical Center, \\ Amsterdam, The Netherlands
}

\section{Key Words \\ Macrophage $\cdot$ Phagocytosis $\cdot$ Pathogen $\cdot$ Marginal zone $\cdot$ Iron}

\begin{abstract}
In the different compartments of the spleen, macrophage populations can be found that have different functions depending on their localization. In the lymphoid compartment of the spleen, the white pulp, macrophages are in essence similar to populations found in lymph nodes and other organized secondary lymphoid organs. In the red pulp, large populations of classical scavenger macrophages are found that, in addition to scavenging blood-borne debris, are involved in iron recycling by phagocytosis of effete red blood cells. The most conspicuous macrophage populations of the spleen are located in the marginal zone. Strategically positioned in the bloodstream and adorned with unique sets of pattern recognition receptors, they play an important role in host defense by bridging the innate and adaptive immune systems. In this review, the various macrophage subsets of the spleen are described.

Copyright $\odot 2012$ S. Karger AG, Basel
\end{abstract}

\section{Introduction}

The spleen is the largest secondary lymphoid organ in our body. Its crucial role in filtering the blood is best illustrated by asplenic individuals, who have a 50 -fold higher risk of developing sepsis and meningitis due to infections with encapsulated bacteria such as Neisseria meningitidis, Streptococcus pneumoniae and Haemophilus influenzae [1]. In essence, the spleen is structured around the branches of the splenic artery, which eventually end in venous sinuses. The arterial branches, called central arterioles, are surrounded by a layer of lymphoid tissue as a continuous sheath, the white pulp. It consists of $\mathrm{T}$ cell areas and B cell follicles, closely resembling the organization found in lymph nodes, except for the apparent absence of high endothelial venules. Although smaller branches of the central arteriole run through the white pulp, most of the arterial blood ends in a sinusoid system in the area surrounding the $\mathrm{T}$ and $\mathrm{B}$ cell zones, thereby forming an anatomical border surrounding the white pulp, the marginal zone $[2,3]$. It is here that the blood opens up in sinusoid spaces formed by sinus lining cells continuous with the endothelium of the arterioles. Especially in rodents, the marginal zone is a conspicuous area consisting of a network of sinus lining cells and reticular fibroblasts through which the blood freely percolates on its way to the red pulp. Macrophage populations and marginal zone B cells are firmly attached to this network, thus allowing a continuous scan of the blood for pathogens and debris. In humans, the marginal zone can be divided into an inner and outer area with a small rim of $\mathrm{T}$ cell zone in between and surrounded by a more diffuse perifollicular zone where macrophages can be found which surround the endings of blood vessels $[4,5]$. From the marginal zone, the blood runs through the red pulp

\section{KARGER}

Fax +4161306 1234

E-Mail karger@karger.ch

www.karger.com
(C) 2012 S. Karger AG, Basel

$1662-811 X / 12 / 0046-0437 \$ 38.00 / 0$

Accessible online at:

www.karger.com/jin
Prof. Dr. Georg Kraal

Department of Molecular Cell Biology and Immunology

Vrije University Medical Center

PO Box 7057, NL-1007 MB Amsterdam (The Netherlands)

Tel. +31 20444 8073, E-Mail G.kraal@vumc.nl 
cords into the venous sinuses, whereby the structure of the venous cords and sinuses, forming the spleen's red pulp, leads to a functional slow bloodstream, enabling the spleen to exert its function as a filter of the blood. The passage from the cords into the sinuses is an important step for the selection of effete red blood cells and their removal by the macrophages of the red pulp. All three major compartments of the spleen, the white pulp, the marginal zone and the red pulp, seem to have their own discrete populations of macrophages, each exerting a somewhat different function based on their specific location.

\section{Macrophages in the Marginal Zone}

Within the reticular framework of the marginal zone, two types of macrophages can be found that are unique for this area. These are the marginal zone macrophages and the marginal metallophilic macrophages. These two subsets are characterized by the specific expression of SIGN-R1 on marginal zone macrophages and CD169 (siglec-1, sialoadhesin) on marginal metallophilic macrophages. In addition to the resident population of marginal zone B cells, many cell types present in the blood pass through the marginal zone, including lymphocytes and granulocytes. In addition, a rather large number of dendritic cells (DCs) is thought to reside temporarily in the marginal zone and to migrate into the white pulp after stimulation and antigen uptake. Also, lymphocytes may dwell here for longer periods during the process of transmigration into the white pulp. It is tempting to assume that both DCs and lymphocytes will interact with these macrophages. Recent studies have demonstrated that along with their important innate functions, macrophages in the marginal zone also promote adaptive immune responses and thereby bridge the innate and adaptive immunity.

\section{Marginal Zone and Marginal Metallophilic}

\section{Macrophages Phagocytose Blood-Borne Pathogens}

As a result of the specific anatomy of the marginal zone, the blood flow slows down and pathogens present in the systemic circulation can be phagocytosed by both the marginal zone macrophages as well as the metallophilic macrophages in this area [3, 4]. Since marginal metallophilic and marginal zone macrophages are notoriously hard to isolate, and elimination procedures such as clodronate liposome treatment generally result in the elimination of both subsets, there are scarce data on the spe- cific or exclusive roles of these two macrophage subsets in the uptake and eradication of pathogens. Specific transgenic mouse models in which one or the other subset could selectively be deleted, such as the CD169-DTR mouse, may provide such information. Unfortunately, in this model, elimination of the $\mathrm{CD}_{169}{ }^{+}$marginal metallophilic macrophages also led to nonspecific elimination of the SIGN-R1-expressing marginal zone macrophages [6].

Nevertheless, there are several reports that show specific involvement of the various pathogen receptors on the macrophage subsets in the recognition and elimination of certain pathogens, in particular encapsulated bacteria. The C-type lectin SIGN-R1, present on marginal zone macrophages, mediates the recognition of pneumococcal saccharides and is essential for S. pneumoniae clearance [7-10]. Scavenger receptor A and macrophage receptor with collagenous structure, which are present to a high degree on marginal zone macrophages, but also CD169, present on metallophilic macrophages, have been implicated in the binding of meningococci $[11,12]$. CD169 has also been shown to function as an uptake receptor for Campylobacter jejuni [13]. Experimental models in which splenic macrophages have been eliminated through the uptake of clodronate liposomes show that trapping of Listeria monocytogenes in the spleen and fast control of infection are lost in the absence of splenic macrophages in the marginal zone [14]. A recent study shows that though L. monocytogenes is initially taken up by multiple cell types, the marginal zone macrophages seem to show microbicidal activity [15]. In addition, Ly6C-expressing monocytes give rise to DCs that help to contain Listeria infection by production of tumor necrosis factor and inducible nitric oxide synthase [16].

In addition to clearance of bacteria, both types of macrophages in the marginal zone are also involved in the degradation and clearance of viruses, such as adenovirus serotype 5 and cowpox virus $[17,18]$. The clearance of lymphocytic choriomeningitis virus by macrophages in the marginal zone was found to be crucial to prevent spreading of viral infection to peripheral organs [19]. CD169 has been described to be a specific uptake receptor for porcine reproductive and respiratory syndrome virus [20], but other non-cell-type-specific receptors such as $\beta 3$-integrins are responsible for the uptake of adenovirus serotype 5 by macrophages [17]. Along with bacterial and viral pathogens, parasites such as Leishmania donovani amastigotes are also preferentially taken up by both marginal metallophilic macrophages and marginal zone macrophages [21], while Trypanosoma cruzi has been shown to bind to CD169 in vitro [22]. 
Taken together, these studies clearly demonstrate the filtering capacity of the macrophages in the marginal zone of the spleen and their relevance in clearing pathogens from the systemic circulation, based on the expression of a large variety of pathogen receptor molecules.

\section{Inflammatory Cytokine Production by Macrophages in the Marginal Zone}

Since macrophages in the marginal zone are often the first cells that encounter pathogens, inflammatory cytokine production by these cell types is important to ensure further action of the innate immune response. Both marginal metallophilic macrophages and marginal zone macrophages can make type I interferon (IFN) after intravenous herpes simplex infection [23]. After Leishmania infection, IFN regulatory factor 7 is upregulated in both types of macrophages and is also essential for the microbicidal activity of the macrophages [24]. These observations are similar to the observed type I IFN production by lymph node subcapsular sinus macrophages in response to virus and suggest that macrophages in the marginal zone have a similar important function in preventing further viral infection via type I IFN production [25]. In addition to type I IFN, production of interleukin (IL)- $1 \alpha$ has been reported to be essential for further stimulation of proinflammatory cytokines and chemokines by splenic macrophages in response to adenovirus [17]. During bacterial sepsis, tumor necrosis factor- $\alpha$ is produced by myeloid cells, and histological analysis shows that both types of macrophages in the marginal zone, in addition to red pulp macrophages, are responsible for this production $[26,27]$. Besides these few studies, there are no data available on proinflammatory cytokine production by specific macrophage subtypes in response to pathogens, and further studies are necessary to define their specific roles in preventing spreading of viral and bacterial infection and the high inflammatory cytokine levels in sepsis.

\section{Cooperation between Marginal Zone Macrophages and Marginal Zone B Cells}

In the marginal zone, a specific population of $\mathrm{B}$ cells expressing immunoglobulin (Ig) $\mathrm{M}^{+}, \mathrm{CD} 21^{\text {high }}, \mathrm{CD} 23^{\text {low }}$ and $\mathrm{CD} 1 \mathrm{~d}^{+}$can be distinguished that provide the early $\mathrm{T}$ cell-independent antipolysaccharide $\operatorname{IgM}$ response. These marginal zone B cells take up antigens via their complement receptor, migrate into $\mathrm{B}$ cell follicles and deposit antigens on follicular dendritic cells (FDCs), which drives the germinal center reaction and the development of high-affinity isotype-switched memory B cells and plasma cells [28]. Interestingly, marginal zone macrophages and marginal zone $B$ cells functionally depend on each other. Apparently, SIGN-R1 expression on macrophages is closely regulated by marginal zone B cells. In the absence of marginal zone B cells, marginal zone macrophages quickly lose SIGN-R1 expression and their phagocytic activity for its ligands [29]. In turn, marginal zone B cells can only capture SIGN-R1 ligands when SIGN-R1-positive marginal zone macrophages are present, and the binding of pathogens to marginal zone $\mathrm{B}$ cells and the development of early IgM responses to polysaccharides are impaired in the absence of SIGN-R1 [30]. Furthermore, FDC deposition of pneumococcal saccharides is absent in SIGN-R1-deficient mice [31]. Marginal zone macrophages have been shown to exhibit a unique classical complement fixation pathway involving SIGNR1. SIGN-R1 binding to $S$. pneumoniae polysaccharides leads directly to binding of $\mathrm{Clq}$ and formation of the $\mathrm{C} 3$ convertase complex without the need for Igs [31]. Thereby, pneumococcal polysaccharide binding to SIGN-R1 leads to complement deposition, which enables the binding of the pathogen to complement receptors on marginal zone B cells which migrate to the B cell follicles and hand over the pathogen to the FDCs. While this mechanism clearly explains the important role of SIGN-R1 in pneumococcal disease, it is not clear whether SIGN-R1mediated complement fixation is essential for other pathogens or described ligands of SIGN-R1 such as $\alpha 2,6$ sialylated Fc forms of IgG (see below).

In conclusion, these findings illustrate the cross-talk between marginal zone B cells and marginal zone macrophages and their interdependence in activating an antipolysaccharide Ig response.

\section{Marginal Metallophilic Macrophages and Follicular $B$ Cells}

Marginal metallophilic macrophages form a border surrounding $B$ cell follicles, and the presence of marginal metallophilic macrophages is dependent on follicular B cells [32]. Most likely, lymphotoxin- $\alpha \beta$ production by follicular B cells is essential for marginal metallophilic macrophages, as has been shown for $\mathrm{CD} 169^{+}$subcapsular sinus macrophages [33]. During immune responses, marginal metallophilic macrophages have been described to enter the B cell follicles [34-36], and CD169-deficient mice have slightly decreased follicular B cell and IgM levels but normal IgG levels [37]. However, no direct role of marginal metallophilic macrophages in the activation of follicular B cells has been described. In contrast, the lymph node counterparts of marginal metallophilic mac- 
rophages, the $\mathrm{CD} 169^{+}$subcapsular sinus macrophages, have clearly been shown to play important roles in B cell immunity. Intravital microscopy studies demonstrate that they actively take up immune complexes and virus particles from the subcapsular sinus and transfer these to $\mathrm{B}$ cells for deposition on FDCs [33, 38-40]. Interestingly, the particles are not phagocytosed but rather move on the surface of $\mathrm{CD} 169^{+}$macrophages from the subcapsular sinus to the underlying B cells. In fact, subcapsular sinus $\mathrm{CD}_{169^{+}}$macrophages have low lysosomal activity [33]. These studies show that this mechanism of particulate antigen uptake by subcapsular sinus macrophages and transfer to B cells enhances humoral immune responses, though adaptive immune responses can be elicited in the absence of these macrophages [25]. It is tempting to speculate that marginal metallophilic macrophages in the marginal zone have similar functions in the uptake of blood-borne antigens and the transfer to $\mathrm{B}$ cells and subsequent FDC deposition. Interestingly, two recent papers showed that the migration of splenic follicular B cells to the outer follicle is induced by binding of oxysterol to Epstein-Barr virus-induced $G$ protein-coupled receptor 2 on the B cells [41, 42]. In mice deficient for the EpsteinBarr virus-induced $G$ protein-coupled receptor 2 or deficient in the production of oxysterol, this migration is impaired and leads to a reduced plasma cell response after an immune challenge. It is suggested that these oxysterols are specifically produced by marginal metallophilic macrophages $[41,42]$. Further studies are necessary to determine the precise role of marginal metallophilic macrophages in the induction of humoral responses.

\section{Marginal Zone Macrophages, Intravenous Ig \\ Treatment and Autoimmunity}

Intravenous Ig treatment is used for the treatment of a number of different autoimmune diseases and consists of the intravenous injection of high doses of polyclonal IgG antibodies. Work by Anthony et al. [43] showed that SIGN-R1 on marginal zone macrophages specifically recognized $\alpha 2,6$-sialylated $F_{c}$ forms present in the intravenous Ig preparation. $\alpha 2,6$-Sialylated IgG Fc has a 10 -fold lower binding affinity for Fc receptor but is specifically bound by SIGN-R1 and also by human DC-SIGN [43]. More recently, using humanized DC-SIGN mice, SIGNR1 or DC-SIGN ligation has been shown to induce a cascade of IL-33 production, causing IL-4 production in basophils which subsequently upregulates the inhibitory Fc $\gamma$ receptor IIB on effector myeloid cells. These increased levels of Fcy receptor IIB on effector macrophages alter the threshold of activation by (auto)immune complexes [44] and thereby result in suppression of autoimmune disease. This is a very new mechanism of suppression, and further studies are necessary to determine whether SIGN-R1-mediated recognition of other antigens such as pneumococcal polysaccharides also results in IL-33/IL-4-mediated suppression.

\section{Marginal Metallophilic Macrophages and T Cell Immunity}

Early studies on the role of macrophages in the marginal zone in which both marginal metallophilic macrophages and marginal zone macrophages were eliminated via clodronate liposomes showed that $\mathrm{T}$ cell responses could be induced in the absence of the two types of macrophage cells $[14,19]$. Similarly, depletion of subcapsular sinus macrophages did not result in diminished $\mathrm{T}$ cell responses after vesicular stomatitis virus infection [25]. Since DCs are still present to take up pathogens and to activate naïve $\mathrm{T}$ cells, it is not unexpected that $\mathrm{T}$ cell responses remain functional in the absence of both types of macrophages in the marginal zone. However, it should be noted that the pathogenic load between the control and clodronate-treated mice in these studies will not be comparable because of the filtering function of these macrophages. In addition, the architecture of the spleen will be affected by the clodronate liposome treatment, which may have consequences for the local hemodynamics and the distribution of pathogens. These aspects complicate direct comparison of the activation of $\mathrm{T}$ cells between the clodronate liposome-treated animals and control animals.

Looking at the positioning of DCs with regard to the blood flow in the marginal sinus, it is clear that not many DCs are in direct contact with the blood flow in the marginal sinus. Cross-presenting $\mathrm{CD} 8^{+} \mathrm{DCs}$ are localized in the $\mathrm{T}$ cell areas as well as more towards the red pulp, whereas $\mathrm{CD}^{-}$DCs can be found in a ring outside the marginal zone macrophages and in the bridging channels. The marginal sinus is thought to be lined by mucosal vascular addressin cell adhesion molecule-positive endothelial cells at the border with the white pulp and marginal metallophilic macrophages that limit passive entrance of cells and even larger particulates into the white pulp. Such a defined cellular boundary does not seem to exist between the marginal sinus and the red pulp, and pathogens may move freely into the marginal zone and red pulp, where they can be taken up by DCs that subsequently migrate to the T cell zone. Small proteins may directly diffuse into the $\mathrm{T}$ and $\mathrm{B}$ cell areas through the conduit, but this mechanism is restricted to molecules smaller than $70 \mathrm{kD}$ [45]. Immune complexes 
Fig. 1. Antigen transport into the white pulp and the role of marginal metallophilic macrophages. Antigen can be picked up in the marginal zone by B cells via their complement receptors and transported to the $\mathrm{B}$ cell follicles, where the antigen can be transferred to FDCs and used for B cell activation. In addition, small molecular antigenic fractions ( $<65 \mathrm{kD}$; red dots) can be directly transported by the fibroblastic reticular cell-based conduit system into both the $\mathrm{B}$ cell follicles and the T cell zone. DCs can pick up antigens in the marginal zone directly (blue antigens). Antigens that have a specific structure that can be recognized by CD169 on marginal metallophilic macrophages will be concentrated from the blood (green antigens) and transferred to DCs during their passage to the white pulp.

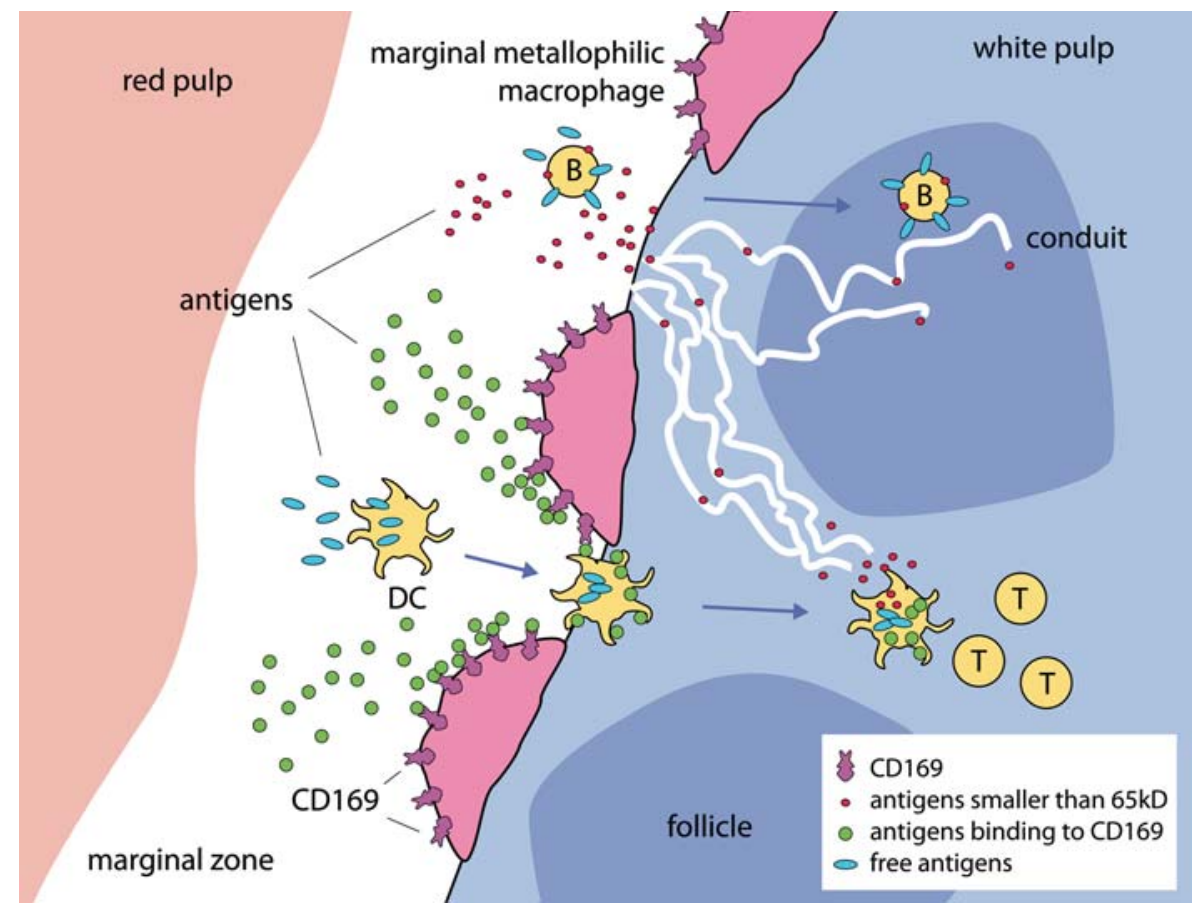

and pathogens would be expected to be transferred to the white pulp in a cell-associated manner, such as on marginal zone B cells and DCs. Indeed, $\mathrm{CD} 8^{+} \mathrm{DCs}$ have been shown to carry L. monocytogenes into the white pulp and to cause spreading of the infection $[46,47]$. Together, these two mechanisms of conduit-mediated transport of small molecules and cell-associated transport of pathogens into the white pulp seemed to be sufficient for the induction of $\mathrm{T}$ cell responses. However, we recently discovered a third mechanism of antigen uptake by marginal metallophilic macrophages and transfer to $\mathrm{CD} 8^{+}$ DCs that results in the activation of T cells [48].

We conjugated ovalbumin (OVA) antigen to antibodies specific for different surface receptors on different types of splenic macrophages and DC subsets and immunized mice intravenously to target antigen-presenting cells in the spleen. Targeting antigen to DEC $205^{+} / \mathrm{CD}^{+}$ DCs resulted in very efficient induction of cytotoxic $\mathrm{T}$ cell responses, as expected. Unexpectedly, targeting to CD169 on marginal metallophilic macrophages resulted in equivalently efficient induction of cytotoxic T cell responses. Evaluation by immunofluorescence showed specific labeling of marginal metallophilic macrophages with anti-CD169-OVA complexes. Clodronate liposome treatment abolished T cell induction by CD169 targeting, while DEC205-mediated targeting remained intact. Next, we could show that after CD169 targeting, DCs did indeed present OVA antigen. After in vivo OVA targeting to marginal metallophilic macrophages, $\mathrm{CD}^{+} \mathrm{DCs}$ isolated from the spleen of these mice were able to stimulate OVA-specific OT-I T cells in vitro. These results indicated that there is antigen transfer between marginal metallophilic macrophages and $\mathrm{CD} 8^{+}$DCs. Since $\mathrm{CD} 8^{+} \mathrm{DCs}$ are not located near marginal metallophilic macrophages, we hypothesized that migration due to chemokine receptor signaling was involved. Indeed, inactivation of chemokine receptor signaling by pertussis toxin treatment eliminated the OVA uptake by $\mathrm{CD} 8^{+}$DCs. Along with OVA targeting to marginal metallophilic macrophages via specific antibodies, intravenous adenovirus infection also resulted in the presence of virus-encoded proteins in marginal metallophilic macrophages and in macrophage-dependent activation of cytotoxic $\mathrm{T}$ cell responses. These experiments together show an important role for the marginal metallophilic macrophages, whereby antigens taken up by these cells are transferred to $\mathrm{CD} 8^{+} \mathrm{DCs}$ for the activation of T cells (fig. 1).

\section{Macrophages in the Marginal Zone and the Uptake of Apoptotic Cells and Autoimmunity}

The removal of apoptotic cells by macrophages is essential for maintaining peripheral tolerance, and disrup- 
tion of this process has been shown to lead to autoimmune diseases in both mouse models as well as in human disease. Intravenously injected apoptotic cells are specifically phagocytosed by marginal zone macrophages and metallophilic macrophages, and this results in suppression of immune responses towards cell-associated antigens [6]. In animals with an intact marginal sinus, cell-associated antigens were presented by $\mathrm{CD} 8^{+} \mathrm{DCs}$, which is known to induce tolerance. Elimination of the two types of macrophages in the marginal zone led to delayed clearance of the apoptotic cells, engulfment and presentation by $\mathrm{CD}^{-}$DCs and loss of tolerance induction with apoptotic cells [6]. Others have shown that elimination of both metallophilic and marginal zone macrophages resulted in uptake of apoptotic cells by red pulp macrophages, increased localization of apoptotic cells in the white pulp, increased production of inflammatory cytokines, decreased production of transforming growth factor- $\beta$ and accelerated induction of autoimmune disease [49]. Together, these studies indicate that uptake of apoptotic cells by macrophages in the marginal zone is essential for the maintenance of peripheral tolerance and the prevention of autoimmune disease.

Since all elimination protocols remove both the metallophilic as well as the marginal zone macrophages, it is unclear what is the relative contribution of each subset, and the two macrophage subsets may have different roles in this process. Furthermore, the two types of macrophages may employ different uptake receptors. Both scavenger receptor $\mathrm{A}$ and macrophage receptor with collagenous structure have been implicated in the uptake of apoptotic cells and are highly expressed by marginal zone macrophages and to a much lower extent by metallophilic macrophages [50]. In contrast, metallophilic marginal zone macrophages express Treml-4 and Tim-4, which mediate the uptake of apoptotic cells [51, 52]. Other recently described receptors for the recognition and uptake of apoptotic cells have not yet been characterized on macrophages in the marginal zone [53], but it is clear that macrophages in the marginal zone express multiple receptors involved in the uptake of apoptotic cells.

\section{Macrophages in the White Pulp}

Both the T cell zone of the white pulp, the periarteriolar sheath, as well as the B cell follicles contain discrete macrophage populations. Interestingly, little is known about the origin and life span of these populations. It is obvious that they are not unique to the spleen but are an integral part of the lymphoid parts of all secondary lymphoid organs.

\section{Tingible Body Macrophages in B Cell Follicles}

In the B cell follicles, macrophages play an important role in the clearance of apoptotic B cells that arise during the germinal center reaction in the process of somatic hypermutation and isotype switching. Germinal centers are antigen-driven structures that arise in the center of the follicle, with a light zone facing the site of antigen entry and a dark zone towards the T cell area. In the light zone, FDCs retain immune complexes and $\mathrm{B}$ cells probe the surface of these cells for antigen. This will lead to a selection process for high-affinity B cells that will undergo further editing of their B cell receptors through hypermutation. This differentiation into high-affinity plasma cells and memory cells is facilitated by the cognate interaction with follicular helper T cells [54]. Intrinsic to the randomness of receptor editing is the large chance of failure. B cells that are unable to form appropriate receptors will die of apoptosis and are cleared by the macrophages in the germinal center. During intensive germinal center reactions, this is obvious from the large, conspicuous macrophages in the germinal center, known as tingible body macrophages, whereby the 'tingible bodies' represent condensed apoptotic nuclei. Important for the uptake of apoptotic cells by macrophages is the expression of phosphatidyl serine on the outer surface of the apoptotic cells that can be recognized by multiple receptors [53]. Tingible body macrophages have been shown to express the tyrosine kinase Mer, the milk fat globule epidermal growth factor 8 and Tim-4, which mediate engulfment of apoptotic cells [52]. While milk fat globule epidermal growth factor 8 is only found in tingible body macrophages [55], Mer has also been shown to be expressed by $\mathrm{F} 4 / 80^{+}$red pulp macrophages and DCs but not by the two types of macrophages in the marginal zone [56].

It is essential that the uptake of apoptotic cells does not lead to a proinflammatory reaction by the macrophages. The importance of this selection can be inferred from studies in mice with defects in the apoptotic uptake pathway. These mice developed severe signs of autoimmune disease, either because B cells eventually died of necrosis, leading to inflammation, or because the lack of negative selection during receptor editing led to the development of autoreactive B cells. 
Macrophages in the T Cell Area

The role of macrophages in the $\mathrm{T}$ cell area of the white pulp is less well understood. This population can be found in all comparable $\mathrm{T}$ cell zones of the secondary lymphoid organs. In the mouse, they lack F4/80 expression and also do not express the various receptors found on the nearby marginal zone macrophages. It could be that they are descendants of patrolling monocytes that have entered the white pulp from the blood. Their position amidst $T$ cells suggests a role in antigen presentation or removal of dying lymphocytes.

\section{Macrophages in the Red Pulp}

The arterial blood ends in red pulp cords that consist of fibroblasts and reticular fibers and form an open blood system without endothelial lining. It is in these cords that a large number of $\mathrm{F} 4 / 80^{+}$macrophages can be found, associated with the reticular cells of these areas and collectively called red pulp macrophages. From the cords, the blood passes into the venous sinuses of the red pulp, which are lined by discontinuous endothelium, with stress fibers extending underneath the basal plasma membrane, parallel to the cellular axis. This arrangement of stress fibers together with the parallel arrangement of the sinus endothelial cells forces the blood in the red pulp through slits formed by stress fibers [4]. This passage becomes difficult for ageing red blood cells with stiffening membranes, such that they stick in the cords and become phagocytosed by the red pulp macrophages. This erythrophagocytosis is important for the turnover of red blood cells, and recycling of iron is a major task of the red pulp macrophages, made possible by the special structure of the red pulp.

Iron from the red blood cells is either released from the macrophage or stored by the cell as ferritin, a cytosolic protein [57]. For the storage of larger amounts of iron in the cell, ferritin can aggregate into hemosiderin, an insoluble complex of partially degraded ferritin, deposits of which can easily be observed in red pulp macrophages. Release of iron from the macrophage can occur as ferritin or as low-molecular weight species that will bind rapidly to plasma transferrin, which acts as a transporter protein [57]. In addition to the phagocytosis of erythrocytes, a considerable percentage of erythrocytes are destroyed intravascularly throughout the body. The released hemoglobin will complex with haptoglobin and is scavenged from the blood by red pulp macrophages via endocytosis through CD163 [58]. Iron release from the storage in splenic macrophages is regulated by the requirements from the bone marrow.

Interestingly, the red pulp is also a large reservoir of monocytes, clustered in red pulp cords. This population outnumbers that in the total circulation and can be rapidly mobilized to leave the spleen and participate in ongoing infections [59].

\section{Conclusion}

Macrophages form essential constituents of the different compartments of the spleen based on the function that each compartment has in maintaining homeostasis of the body. The majority of macrophages that we encounter in the spleen can be regarded as scavenger cells pur sang that, based on the compartment and the phagocytosed material, activate pro- or anti-inflammatory responses. The most conspicuous populations of spleen macrophages can be found in the marginal zone, where two highly specialized populations are well equipped to react to a variety of pathogens. Of these two, the marginal metallophilic macrophage has unique capabilities to aid in establishing $\mathrm{T}$ cell immune responses, thereby bridging innate and adaptive immunity.
References
Ram S, Lewis LA, Rice PA: Infections of people with complement deficiencies and patients who have undergone splenectomy. Clin Microbiol Rev 2010;23:740-780.

-2 Schmidt EE, MacDonald IC, Groom AC: Comparative aspects of splenic microcirculatory pathways in mammals: the region bordering the white pulp. Scanning Microsc 1993;7:613-628.

3 Kraal G: Cells in the marginal zone of the spleen. Int Rev Cytol 1992;132:31-74.
Macrophage Subpopulations in the Spleen
J Innate Immun 2012;4:437-445 
6 Miyake Y, Asano K, Kaise H, Uemura M, Nakayama M, Tanaka M: Critical role of macrophages in the marginal zone in the suppression of immune responses to apoptotic cell-associated antigens. J Clin Invest 2007; 117:2268-2278

-7 Geijtenbeek TB, Groot PC, Nolte MA, van Vliet SJ, Gangaram-Panday ST, van Duijnhoven GC, Kraal G, van Oosterhout AJ, van Kooyk Y: Marginal zone macrophages express a murine homologue of DC-SIGN that captures blood-borne antigens in vivo. Blood 2002;100:2908-2916.

8 Kang YS, Kim JY, Bruening SA, Pack M, Charalambous A, Pritsker A, Moran TM, Loeffler JM, Steinman RM, Park CG: The C-type lectin SIGN-R1 mediates uptake of the capsular polysaccharide of Streptococcus pneumoniae in the marginal zone of mouse spleen. Proc Natl Acad Sci USA 2004;101: 215-220.

-9 Lanoue A, Clatworthy MR, Smith P, Green S, Townsend MJ, Jolin HE, Smith KG, Fallon PG, McKenzie AN: SIGN-R1 contributes to protection against lethal pneumococcal infection in mice. J Exp Med 2004;200:13831393.

10 Koppel EA, Saeland E, de Cooker DJ, van Kooyk Y, Geijtenbeek TB: DC-SIGN specifically recognizes Streptococcus pneumoniae serotypes 3 and 14. Immunobiology 2005; 210:203-210.

-11 Pluddemann A, Mukhopadhyay S, Sankala M, Savino S, Pizza M, Rappuoli R, Tryggvason K, Gordon S: SR-A, MARCO and TLRs differentially recognise selected surface proteins from Neisseria meningitidis: an example of fine specificity in microbial ligand recognition by innate immune receptors. J Innate Immun 2009;1:153-163.

$\checkmark 12$ Jones C, Virji M, Crocker PR: Recognition of sialylated meningococcal lipopolysaccharide by siglecs expressed on myeloid cells leads to enhanced bacterial uptake. Mol Microbiol 2003;49:1213-1225.

-13 Heikema AP, Bergman MP, Richards H, Crocker PR, Gilbert M, Samsom JN, van Wamel WJ, Endtz HP, van Belkum A: Characterization of the specific interaction between sialoadhesin and sialylated Campylobacter jejuni lipooligosaccharides. Infect Immun 2010;78:3237-3246.

14 Aichele P, Zinke J, Grode L, Schwendener RA, Kaufmann SH, Seiler P: Macrophages of the splenic marginal zone are essential for trapping of blood-borne particulate antigen but dispensable for induction of specific $\mathrm{T}$ cell responses. J Immunol 2003;171:11481155.

15 Aoshi T, Carrero JA, Konjufca V, Koide Y, Unanue ER, Miller MJ: The cellular niche of Listeria monocytogenes infection changes rapidly in the spleen. Eur J Immunol 2009; 39:417-425.
16 Shi C, Pamer EG: Monocyte recruitment during infection and inflammation. Nat Rev Immunol 2011;11:762-774.

17 Di Paolo NC, Miao EA, Iwakura Y, MuraliKrishna K, Aderem A, Flavell RA, Papayannopoulou T, Shayakhmetov DM: Virus binding to a plasma membrane receptor triggers interleukin-1 alpha-mediated proinflammatory macrophage response in vivo. Immunity $2009 ; 31: 110-121$.

18 Hsu KM, Pratt JR, Akers WJ, Achilefu SI, Yokoyama WM: Murine cytomegalovirus displays selective infection of cells within hours after systemic administration. J Gen Virol 2009;90:33-43.

19 Seiler P, Aichele P, Odermatt B, Hengartner $\mathrm{H}$, Zinkernagel RM, Schwendener RA: Crucial role of marginal zone macrophages and marginal zone metallophils in the clearance of lymphocytic choriomeningitis virus infection. Eur J Immunol 1997;27:2626-2633.

20 Vanderheijden N, Delputte PL, Favoreel HW, Vandekerckhove J, Van Damme J, van Woensel PA, Nauwynck HJ: Involvement of sialoadhesin in entry of porcine reproductive and respiratory syndrome virus into porcine alveolar macrophages. J Virol 2003; 77:8207-8215.

21 Gorak PM, Engwerda CR, Kaye PM: Dendritic cells, but not macrophages, produce IL-12 immediately following Leishmania donovani infection. Eur J Immunol 1998;28: 687-695.

22 Monteiro VG, Lobato CS, Silva AR, Medina DV, de Oliveira MA, Seabra SH, de Souza W, DaMatta RA: Increased association of Trypanosoma cruzi with sialoadhesin positive mice macrophages. Parasitol Res 2005;97: 380-385.

23 Eloranta ML, Alm GV: Splenic marginal metallophilic macrophages and marginal zone macrophages are the major interferon-alpha/beta producers in mice upon intravenous challenge with herpes simplex virus. Scand J Immunol 1999;49:391-394.

24 Phillips R, Svensson M, Aziz N, Maroof A, Brown N, Beattie L, Signoret N, Kaye PM: Innate killing of Leishmania donovani by macrophages of the splenic marginal zone requires IRF-7. PLoS Pathog 2010; 6:e1000813.

25 Iannacone M, Moseman EA, Tonti E, Bosurgi L, Junt T, Henrickson SE, Whelan SP, Guidotti LG, von Andrian UH: Subcapsular sinus macrophages prevent CNS invasion on peripheral infection with a neurotropic virus. Nature 2010;465:1079-1083.

26 Grivennikov SI, Tumanov AV, Liepinsh DJ, Kruglov AA, Marakusha BI, Shakhov AN, Murakami T, Drutskaya LN, Forster I, Clausen BE, Tessarollo L, Ryffel B, Kuprash DV, Nedospasov SA: Distinct and nonredundant in vivo functions of TNF produced by $t$ cells and macrophages/neutrophils: protective and deleterious effects. Immunity 2005;22: 93-104.
27 Rosas-Ballina M, Ochani M, Parrish WR, Ochani K, Harris YT, Huston JM, Chavan S, Tracey KJ: Splenic nerve is required for cholinergic antiinflammatory pathway control of TNF in endotoxemia. Proc Natl Acad Sci USA 2008;105:11008-11013.

28 Cinamon G, Zachariah MA, Lam OM, Foss FW Jr, Cyster JG: Follicular shuttling of marginal zone B cells facilitates antigen transport. Nat Immunol 2008;9:54-62.

29 You Y, Myers RC, Freeberg L, Foote J, Kearney JF, Justement LB, Carter RH: Marginal zone $\mathrm{B}$ cells regulate antigen capture by marginal zone macrophages. J Immunol 2011; 186:2172-2181.

30 Koppel EA, Litjens M, van den Berg VC, van Kooyk Y, Geijtenbeek TB: Interaction of SIGNR1 expressed by marginal zone macrophages with marginal zone B cells is essential to early IgM responses against Streptococcus pneumoniae. Mol Immunol 2008;45:28812887.

-31 Kang YS, Do Y, Lee HK, Park SH, Cheong C, Lynch RM, Loeffler JM, Steinman RM, Park CG: A dominant complement fixation pathway for pneumococcal polysaccharides initiated by SIGN-R1 interacting with C1q. Cell 2006;125:47-58.

32 Nolte MA, Arens R, Kraus M, van Oers MH, Kraal G, van Lier RA, Mebius RE: B cells are crucial for both development and maintenance of the splenic marginal zone. J Immunol 2004; 172:3620-3627.

33 Phan TG, Green JA, Gray EE, Xu Y, Cyster JG: Immune complex relay by subcapsular sinus macrophages and noncognate B cells drives antibody affinity maturation. Nat Immunol 2009;10:786-793.

34 Martinez-Pomares L, Kosco-Vilbois M, Darley E, Tree P, Herren S, Bonnefoy JY, Gordon $S:$ Fc chimeric protein containing the cysteine-rich domain of the murine mannose receptor binds to macrophages from splenic marginal zone and lymph node subcapsular sinus and to germinal centers. J Exp Med 1996;184:1927-1937.

35 Yu P, Wang Y, Chin RK, Martinez-Pomares L, Gordon S, Kosco-Vibois MH, Cyster J, Fu YX: B cells control the migration of a subset of dendritic cells into B cell follicles via CXC chemokine ligand 13 in a lymphotoxin-dependent fashion. J Immunol 2002;168:51175123.

36 Junt T, Scandella E, Ludewig B: Form follows function: lymphoid tissue microarchitecture in antimicrobial immune defence. Nat Rev Immunol 2008;8:764-775.

37 Oetke C, Vinson MC, Jones C, Crocker PR: Sialoadhesin-deficient mice exhibit subtle changes in B- and T-cell populations and reduced immunoglobulin $\mathrm{M}$ levels. Mol Cell Biol 2006;26:1549-1557. 
-38 Junt T, Moseman EA, Iannacone M, Massberg S, Lang PA, Boes M, Fink K, Henrickson SE, Shayakhmetov DM, Di Paolo NC, van Rooijen N, Mempel TR, Whelan SP, von Andrian UH: Subcapsular sinus macrophages in lymph nodes clear lymph-borne viruses and present them to antiviral B cells. Nature 2007;450:110-114.

-39 Phan TG, Grigorova I, Okada T, Cyster JG: Subcapsular encounter and complement-dependent transport of immune complexes by lymph node B cells. Nat Immunol 2007;8: 992-1000.

-40 Carrasco YR, Batista FD: B cells acquire particulate antigen in a macrophage-rich area at the boundary between the follicle and the subcapsular sinus of the lymph node. Immunity 2007;27:160-171.

-41 Liu C, Yang XV, Wu J, Kuei C, Mani NS, Zhang L, Yu J, Sutton SW, Qin N, Banie H, Karlsson L, Sun S, Lovenberg TW: Oxysterols direct B-cell migration through EBI2. Nature 2011;475:519-523.

42 Hannedouche S, Zhang J, Yi T, Shen W, Nguyen D, Pereira JP, Guerini D, Baumgarten BU, Roggo S, Wen B, Knochenmuss R, Noel S, Gessier F, Kelly LM, Vanek M, Laurent S, Preuss I, Miault C, Christen I, Karuna R, Li W, Koo DI, Suply T, Schmedt C, Peters EC, Falchetto R, Katopodis A, Spanka C, Roy MO, Detheux M, Chen YA, Schultz PG, Cho CY, Seuwen K, Cyster JG, Sailer AW: Oxysterols direct immune cell migration via EBI2. Nature 2011;475:524-527.

-43 Anthony RM, Wermeling F, Karlsson MC, Ravetch JV: Identification of a receptor required for the anti-inflammatory activity of IVIG. Proc Natl Acad Sci USA 2008;105: 19571-19578.

44 Anthony RM, Kobayashi T, Wermeling F, Ravetch JV: Intravenous gammaglobulin suppresses inflammation through a novel T(H)2 pathway. Nature 2011;475:110-113.
45 Nolte MA, Belien JA, Schadee-Eestermans I, Jansen W, Unger WW, van Rooijen N, Kraal G, Mebius RE: A conduit system distributes chemokines and small blood-borne molecules through the splenic white pulp. J Exp Med 2003;198:505-512.

46 Aoshi T, Zinselmeyer BH, Konjufca V, Lynch JN, Zhang X, Koide Y, Miller MJ: Bacterial entry to the splenic white pulp initiates antigen presentation to CD8+ T cells. Immunity 2008;29:476-486.

47 Edelson BT, Bradstreet TR, Hildner K, Carrero JA, Frederick $\mathrm{KE}$, Wumesh $\mathrm{KC}, \mathrm{Be}$ lizaire R, Aoshi T, Schreiber RD, Miller MJ, Murphy TL, Unanue ER, Murphy KM: $\operatorname{CD} 8 \alpha(+)$ dendritic cells are an obligate cellular entry point for productive infection by Listeria monocytogenes. Immunity 2011;35: 236-248.

48 Backer R, Schwandt T, Greuter M, Oosting M, Jungerkes F, Tuting T, Boon L, O’Toole T, Kraal G, Limmer A, den Haan JM: Effective collaboration between marginal metallophilic macrophages and CD8+ dendritic cells in the generation of cytotoxic T cells. Proc Natl Acad Sci USA 2010;107:216-221.

49 McGaha TL, Chen Y, Ravishankar B, van Rooijen N, Karlsson MC: Marginal zone macrophages suppress innate and adaptive immunity to apoptotic cells in the spleen. Blood 2011;117:5403-5412.

50 Wermeling F, Chen Y, Pikkarainen T, Scheynius A, Winqvist O, Izui S, Ravetch JV, Tryggvason K, Karlsson MC: Class A scavenger receptors regulate tolerance against apoptotic cells, and autoantibodies against these receptors are predictive of systemic lupus. J Exp Med 2007;204:2259-2265.

51 Hemmi H, Idoyaga J, Suda K, Suda N, Kennedy K, Noda M, Aderem A, Steinman RM: A new triggering receptor expressed on myeloid cells (Trem) family member, Trem-like 4 , binds to dead cells and is a DNAX activation protein 12-linked marker for subsets of mouse macrophages and dendritic cells. J Immunol 2009;182:1278-1286.
52 Wong K, Valdez PA, Tan C, Yeh S, Hongo JA, Ouyang W: Phosphatidylserine receptor Tim- 4 is essential for the maintenance of the homeostatic state of resident peritoneal macrophages. Proc Natl Acad Sci USA 2010;107: 8712-8717.

53 Bratton DL, Henson PM: Apoptotic cell recognition: will the real phosphatidylserine receptor(s) please stand up? Curr Biol 2008; 18:R76-R79.

54 King C, Tangye SG, Mackay CR: T follicular helper (TFH) cells in normal and dysregulated immune responses. Annu Rev Immunol 2008;26:741-766.

55 Hanayama R, Tanaka M, Miyasaka K, Aozasa K, Koike M, Uchiyama Y, Nagata S: Autoimmune disease and impaired uptake of apoptotic cells in MFG-E8-deficient mice. Science 2004;304:1147-1150.

56 Rahman ZS, Shao WH, Khan TN, Zhen Y, Cohen PL: Impaired apoptotic cell clearance in the germinal center by Mer-deficient tingible body macrophages leads to enhanced antibody-forming cell and germinal center responses. J Immunol 2010;185:58595868.

57 Knutson M, Wessling-Resnick M: Iron metabolism in the reticuloendothelial system. Crit Rev Biochem Mol Biol 2003;38:61-88.

58 Kristiansen M, Graversen JH, Jacobsen C, Sonne O, Hoffman HJ, Law SK, Moestrup SK: Identification of the haemoglobin scavenger receptor. Nature 2001;409:198-201.

59 Swirski FK, Nahrendorf M, Etzrodt M, Wildgruber M, Cortez-Retamozo V, Panizzi P, Figueiredo JL, Kohler RH, Chudnovskiy A, Waterman P, Aikawa E, Mempel TR, Libby $\mathrm{P}$, Weissleder R, Pittet MJ: Identification of splenic reservoir monocytes and their deployment to inflammatory sites. Science 2009;325:612-616. 